\title{
LITERATUR REVIEW: BUDAYA PERILAKU IBU HAMIL DI INDONESIA \\ Ulfatun Nisa
}

Universitas Islam sultan Agung Semarang, Indonesia E-mail: ulfatunnisa2017@gmail.com

\section{Diterima:}

29 Oktober 2021

Direvisi:

08 November

2021

\section{Disetujui:}

15 November

2021

\section{Abstrak}

Indonesia merupakan negara yang terdiri dari berbagai suku. perbedaan etnis akan menyebabkan perbedaan adat dan kebiasaan. Selama hamil dan melahirkan, masih banyak perilaku dan pantangan yang dilakukan. Berdasarkan hal tersebut, peneliti ingin mengkaji lebih dalam budaya tersebut khususnya mengenai perilaku ibu hamil dan masa nifas. Kajian dilakukan dengan mereview artikel-artikel yang berkaitan dengan hal tersebut di masyarakat lokal di Indonesia. Karena masyarakat lokal di Indonesia masih kental dengan budaya yang ada di rumahnya. Budaya perilaku ibu hamil dari berbagai suku di Indonesia memiliki persamaan yaitu melakukan pemijatan pada perut ibu hamil yang dilakukan oleh paraji atau dukun beranak dan pantangan makanan yang masih dipercayai. Budaya perilaku ibu hamil dari berbagai suku di Indonesia memiliki persamaan yaitu melakukan pemijatan pada perut ibu hamil yang dilakukan oleh paraji atau dukun beranak. Hal tersebut masih dipercayai oleh masyarakat suku banjar, suku baduy dalam dan suku bugis.

Kata kunci: Praktek Budaya, Wanita hamil, perbedaan etnis

\begin{abstract}
Indonesia is a country consisting of various ethnic groups. ethnic differences will lead to differences in customs and habits. During pregnancy and childbirth, there are still many behaviors and taboos that are carried out. Based on this, the researcher wants to examine more deeply the culture, especially regarding the behavior of pregnant women and the postpartum period. The study was conducted by reviewing articles related to this in local communities in Indonesia. Because local people in Indonesia are still thick with the culture in their homes. The behavioral culture of pregnant women from various ethnic groups in Indonesia has similarities, namely doing massage on the abdomen of pregnant women by paraji or traditional birth attendants and food taboos that are still trusted The behavioral culture of pregnant women from various tribes in Indonesia has the same thing that is to massage the stomach of pregnant women carried out by paraji or child shamans. This is still believed by the banjar people, the inner baduy tribe and the bugis tribe.
\end{abstract}

Keywords: Cultural Practices, pregnant Woman 
\begin{tabular}{|l|l|}
\hline & \\
\hline
\end{tabular}

\section{Pendahuluan}

Negara Kesatuan Republik Indonesia (NKRI) merupakan Negara kepulaun terbesar di dunia (Farih 2016). Indonesia terdiri dari beribu-ribu pulau dengan letak geografis yang tidak sama. Sudah bukan menjadi rahasia lagi jika Indonesia memiliki beragam suku, budaya, adat istiadat dan kepercayaan. Budaya dalah nilai-nilai, kepercayaan, sikap dan adat yang terbagi dalam suatu kelompok yang berlanjut dari generasi kegenerasi selanjutnya. Budaya telah digunakan oleh seorang atau suatu kelompok dengan rasa aman dan nyaman dari waktu ke waktu dengan tidak memikirkan kebenarannya. Tiap-tiap suku atau kelompok masyarakat mempunyai peraturan, adat istiadat dan kepercayaan yang berbeda-beda, termasuk dalam hal budaya perilaku ibu saat hamil (Anwar 2019).

Hamil dan melahirkan merupakan keadaan yang alamiah dimana sebagian besar wanita dapat merasakannya (Prasetyaningrum 2017). Dan Seharusnya juga hamil dan melahirkan menjadi peristiwa yang membahagiakan. Namun, seringkali menjadi sebuah petaka. Sebenarnya, hampir seluruh kematian itu dapat dicegah. Namun pada kenyataannya, angka kematian ibu di Indonesia masih tinggi, hal tersebut dikarenakan terjadinya komplikasi pada saat persalinan. Angka kematian ibu (AKI) juga disertai dengan tingginya angka kematian bayi (AKB), angka kematian anak (AKA) (Mariati et al. 2011).

Selain angka kematian, yang masih menjadi salah satu indikator besar lainnya adalah masalah kesehatan reproduksi ibu dan kesehatan anak. Penyakit seperti ISPA, diare, infeksi cacing bahkan tetanus. Penyakit tersebut adalah penyakit yang sering menyerang pada bayi, balita dan juga anak-anak. Dan terkadang penyakit tersebut bahkan menyebabkan kematian pada bayi dan anak-anak. Selain itu juga dengan penyakit yang diderita oleh ibu seperti anemia, hepatitis, hipertensi dan lain-lain juga bisa beresiko pada kematian baik itu sebelum, sedang atau bahkan setelah proses persalinan (Astuti and Ertiana 2018).

Masalah-masalah tersebut baik kematian maupun kesehatan yang terjadi pada ibu dan bayi sebenarnya tidak terlepas dari faktor sosial budaya dan lingkungan dalam lingkup masyarakat dimana mereka tinggal. Disadari atau tidak pengaruh budaya terhadap status kesehatan ibu dan bayi tidak dapat diabaikan begitu saja. Kesehatan adalah bagian menyeluruh dari kebudayaan. Dari berbagai etnis di Indonesia menunjukan bahwa masalah kesehatan ibu dan bayi yang berkaitan dengan budaya kesehatan sungguh meprihatinkan.

\section{Metode Penelitian}

Dalam pencarian artikel peneliti menggunakan pencarian dalam bahasa Indonesia dan bahasa inggris dengan sumber yang relevan yang berhubungan dengan topic. Pencarian artikel dilakukan dengan menggunakan database antara lain Google Scholar. Keyword yang digunakan yaitu "cultural practice", "budaya", "pregnant woman", "ibu hamil". Artikel yang didapatkan dan sesuai dengan kriteria adalah 4 artikel nasional yang kemudian akan direview.

Artikel pertama merupakan penelitian yag dilakukan oleh Mara Ipa,dkk (2016) pada etnik Baduy dalam (Ipa, Prasetyo, and Kasnodihardjo 2016). Metode yang digunakan adalah menggunakan penelitian kualitatif, dalam pengambilan data metode yang dilakukan adalah dengan menggunakan cara mewawancara secara mendalam dan observasi. Dan dalam pemilihan sampel informan peneliti menggunakan teknik purposive sampling pada 
ibu hamil, ibu nifas, dukun beranak atau paraji, bidan desa, ketua adat, tokoh pemuda, tokoh adat, ibu usia subur, remaja puteri dengan jumlah keeluruhannya dari informan adalah sebanyak 15 orang. Hasil yang diperoleh dalam penelitian, peneliti menemukan praktik budaya sebagai pendukung kepatuhan pada pimpinan adat atau biasa disebut dengan kokolot, perayaan tradisi sebagai media promosi program kesehatan, pemanfaatan obat tradisional, pola pemukiman secara kluster. Faktor yang membahayakan tidak ada pemeriksaan medis selama kehamilan, persalinan dan nifas, prosesi melahirkan secara mandiri, tempat persalinan situasional (saung/rumah), lama waktu menunggu paraji, pemotongan tali pusat, usia pertama kali melahirkan, melakukan aktivitas berat, larangan menggunakan pakaian dalam dan pembalut wanita (Yuliani 2019). Artikel kedua merupakan penelitian yang dilakukan oleh Husaini, dkk (2016).

Metode yang dilakukan dalam penelitian ini adalah adalah menggunakan penelitian kualitatif dengan pendekatan analisis isi (content analysis) yang dilakukan di Kecamatan Martapura Timur. Responden disini adalah sebagai subjek dalam penelitian ini adalah ibu yang sedang hamil (trimester 1 sampai trimester tiga) serta ibu nifas yang menjalankan tradisi suku Banjar yang diambil secara purposive sampling yaitu cara untuk menentukan responden dilakukan dengan spontan sesuai dengan persyaratan responden yang diperlukan, 2 orang dukun kampung suku Banjar, dan 1 orang bidan. Sehing jumlah keseluruhan responden dalam penelitian ini berjumlah 7 orang. Hasil dari penelitian ini Perilaku ibu hamil dan ibu nifas suku Banjar di Kecamatan Martapura timur yaitu dalam hal memperoleh perawatan dikelompokan menjadi tiga kelompok yaitu dari dukun kampung, adat istiadat dan dari tenaga kesehatan. Sedangkan pantangan ibu hamil dan nifas dikelompokkan menjadi 3 kategori yaitu pantangan perilaku, makanan dan minuman.

Artikel yang ketiga merupakan penelitian yang dilakukan oleh Arum,P. Siti,A (2010). Metode yang digunakan adalah Metode penelitian kualitatif dengan desain fenomenologis. Sampel diambil dengan tehnik snowball sampling, yang masing-masing kecamatan diambil 10\%, Sampel berjumlah 21 keluarga kemudian dipilih 6 orang dari salah satu anggota keluarga tersebut yang mempunyai anggota keluarga sedang hamil atau nifas,untuk dilakukan interview secara mendalam. Hasil penelitian deskriptif, dari sampel diseluruh kabupaten sukoharja rata-rata 50\% - 75\% masih melalukan upacara penguburan plasenta, mempunyai pantangan dan kebiasaan yang harus dilakukan pada saat hamil, mempunyai pantangan dan kebiasaan yang harus dilakukan saat nifas. Karena hal tersebut maka teridentifikasinya alasan keluarga yang mempunyai perilaku budaya pada masa kehamilan dan nifas adalah dalam upaya mempertahankan kesehatanya. Pada penelitian lebih lanjut bisa dilakukan dengan menspesifikan pada masalah perilaku budaya tertentu.

Artikel keempaat merupakan hasil penelitian dari Hesty (2013). Metode penelitian yang digunakan oleh peneliti adalah jenis penelitian kualitatif yaitu dengan menggunakan pendekatan Etnografi. Cara dalam memilih informan yaitu dengan menggunakan kriteria informan dengan jumlah seluruhnya adalah sebanyak 14 orang. Cara mengumpulan informasi yaitu dengan wawancara mendalam dan observasi, serta untuk kevalidan data dilakukan triangulasi sumber. Untuk mengelolah dan menganalisis data menggunakan analisis isi dan kemudian disajikan dalam bentuk naratif. Hasilnya memperlihatkan bahwa sampai saat ini ritual yang masih dijalankan ibu hamil disuku Bugis Bone yaitu Makkatenni Sanro dan Ma'cera Wettang atau Makkarawa Babua. Dalam hal perawatan ibu hamil juga tidak lepas dari bantuan seorang dukun beranak atau paraji serta banyak pantangan yang harus dipatuhi oleh seorang ibu yang sedang hamil.

\section{Hasil dan Pembahasan}

Dari hasil literature review yang telah dipaparkan semua artikel menjelaskan hasil penelitian tentang berbagai budaya perilaku pada ibu hamil di Indonesia. 
a. Suku Banjar

Wanita - wanita hamil disuku banjar biasanya mengkonsumsi dan mengoleskan minyak bangsul ke perut. Minyak bangsul merupakan nama lain dari minyak kelapa yaitu minyak yang dipercaya oleh suku banjar untuk memudahkan persalinan. Mereka percaya bahwa jika mengoleskan minyak bangsul ke perut persalinannya menjadi lancar meluncur seperti halnya minyak.

Wanita hamil disuku banjar dalam mengkonsumsi minyak bangsul adalah dengan meminumnya setiap pagi dan ketika umur kehamilan mencapai 7 bulan mereka mengoleskan minyak bangsul ke perut. Dalam pandangan medis mengkonsumsi minyak bangsul atau minyak kelapa saat hamil dapat melindungi anak dari efek stress sebelum melahirkan, dan diyakini dapat menyebabkan masalah perkembangan neurologis setelah melahirkan (Sari, Husaini, and Ilmi 2017).

Wanita hamil suku banjar tidak diperkenankan untuk keluar dari rumah maupun hutan saat menjelang waktu maghrib (Rofelawaty 2018). Karena menurut kepercayaan masyarakat suku banjar ibu hamil memiliki aroma tubuh yang sungguh harum, sehingga akan mudah terkena ganggu makhluk halus, secara medis biologis ibu hamil tidak diperkenankan untuk keluar pada malam hari hinga larut (Saputro 2017). Karena udara pada malam hari akan mengancam kondisi ibu dan janin yang disebabkan karena udara malam hari banyak mengandung karbondioksida $(\mathrm{CO} 2)$.

b. Suku Baduy

Wanita hamil disuku baduy melakukan pemijatan pada perut ibu hamil. Biasanya masyarakat baduy dalam melakukan pemijatan perutnya di dukun beranak atau biasa disebut paraji. Masyarakat baduy dalam menyebut ritual pemijatan perut pada ibu hamil itu dengan sebutan ngaragap beuteung. Mereka menyakini bahwa hal tersebut dapat memudahkan ibu hamil dalam menjalani persalinan. Akan menjadi baik kondisi ibu hamil apabila proses pemijatanya dilakukan dengan benar. Lain halnya apabila dalam proses memijat para memberikan terlalu banyak tekanan, maka dampaknya akan mengganggu janin yang ada didalam perut ibu hamil tersebut.

Secara medis tindakan memijat perut ibu hamil pada saat hamil terutama pada masa trimester tiga tidak dibenarkan aman (Majir 2018). Diperbolehkan melakukan pengurutan pada perut ibu hamil jika posisi bayi sungsang, dan itupun tidak dilakukan secara sembarangan. Teknik pemijatan harus dilakukan dengan cara khusus dan dalam pengawasan dokter spesialis kandungan, tidak semua ritual adat tersebut dilakukan. Karena menurut masyarakat baduy itu sendiri mengungkapkan bahwa perawatan kehamilan yang dianggap berbahaya bagi ibu maupun janin sepertinya dapat membahayakan tali pusat (Anak, 2016).

Selain ritual pengurutan perut ibu hamil, wanita-wanita hamil disuku baduy juga dilarang beraktifitas sehari- hari seperti sebelum hamil. Misalnya pergi ke ladang yang jaraknya dari rumah jauh dan juga dengan jalanan yang tidak rata dan cukup berbahaya. Menurut mereka perilaku tersebut sangat beresiko tidak baik untuk kehamilannya.

c. Suku Dayak

Lain halnya dengan suku baduy. Menurut masyarakat suku dayak sangau wanita yang sedang hamil harus tetap melakukan aktifitas seperti biasanya seperti saat sebelum wanita itu hamil. Yang sebagian besar pekerjaan masyarakat suku dayak adalah sebagai petani. 


\section{d. Suku Bugis}

Ma'cerra wettang merupakan ritual budaya yang dilakukan oleh masyarakat bugis pada ibu hamil. Ritual ini dilaksanakan ketika umur ibu hamil (Nasruddin 2017). Memasuki bulan ketujuh atau saat awal masuk masa trimester tiga. Menurut masyarakat bugis ritual ini dapat memperlancar persalinan, dapat membuat posisi janin menjadi sempurna dan dijauhkan dari segala gangguan dari makhluk halus. Prosesi ma'cerra wettang dilakukan oleh dukun beranak atau paraji. Prosesnya yaitu dengan mengurut perut ibu hamil dengan menggunakan minyak goreng yang dicampur dengan bawang merah. Hal itu dapat dipercaya bahwa akan memudahkan ibu dalam melahirkan dan anaknya akan lahir dengan selamat.

e. Suku Jawa

Masyarakat Jawa percaya bahwa wanita yang sedang mengandung tidak diperbolehkan untuk mengkonsumsi telur, mereka percaya jika wanita hamil mengkonsumsi telur maka akan susah saat melakukan persalinan (Intan 2018). Ibu hamil juga dilarang untuk mengkonsumsi daging karena mereka percaya bahwa jika wanita yang sedang hamil mengkonsumsi daging akan menimbulkan pendarahan. Secara medis budaya pantangan makan malah justru akan merugikan kesehatan ibu dan janin yang dikandungnya (Wijaya 2017). Contohnya seperi dilarang mengkonsumsi telur dan daging. Sebenarnya ibu hamil sangat perlu untuk mengkonsumsi telur dan daging gunanya untuk memenuhi kebutuhan gizi ibu hamil dan janin yang dikandungnya juga perlu nutrisi. karena pantangan tersebut ibu hamil dalam memenuhi kebutuhan gizinya menjadi kurang yang pada akhirnya akan menyebabakan ibu menjadi anemia dan kurang energi. Dari hal tersebut saat melakukan persalinan ibu hamil dapat mengalami pendarahan dan berat badan bayi baru lahir rendah.

\section{Kesimpulan}

Budaya perilaku ibu hamil dari berbagai suku di Indonesia memiliki persamaan yaitu melakukan pemijatan pada perut ibu hamil yang dilakukan oleh paraji atau dukun beranak. Hal tersebut masih dipercayai oleh masyarakat suku banjar, suku baduy dalam dan suku bugis. Selain hal budaya dalam perilaku ibu hamil sebagian daerah juga masih percaya pada budaya pantang mengkonsumsi makanan tertentu. Misalnya pada masyarakat jawa, ibu hamil pantang makan telur dan daging. Budaya perilaku dan pantangan makanan yang masih dipercayai oleh masyarakat daerah di indonesia kadang memberikan alasan terkait dengan kesehatan tetapi banyak juga alasan yang kurang bisa diterima dimata kesehatan.

\section{Bibliografi.}

Anak, Dengan Kejadian Tuberkulosis Pada. 2016. "Laporan Penelitian." LPPM UNS.

Anwar, Khalidatul Khair. 2019. "Kearifan Budaya Lokal Dalam Pelayanan Kesehatan Ibu Dan Anak Pada Suku Bajo.” In Prosiding Seminar Nasional, , 58.

Astuti, Reni Yuli, and Dwi Ertiana. 2018. Anemia Dalam Kehamilan. Semarang: Pustaka Abadi.

Farih, Amin. 2016. "Nahdlatul Ulama (NU) Dan Kontribusinya Dalam Memperjuangkan Kemerdekaan Dan Mempertahankan Negara Kesatuan Republik Indonesia (NKRI)." Walisongo: Jurnal Penelitian Sosial Keagamaan 24(2): 251-84.

Intan, Tania. 2018. "Fenomena Tabu Makanan Pada Perempuan Indonesia Dalam Perspektif Antropologi Feminis.” PALASTREN Jurnal Studi Gender 11(2): 233-58.

Ipa, Mara, Djoko Adi Prasetyo, and Kasnodihardjo Kasnodihardjo. 2016. "Praktik Budaya Perawatan Dalam Kehamilan Persalinan Dan Nifas Pada Etnik Baduy Dalam." Indonesian Journal of Reproductive Health 7(1): 25-36.

Majir, Abdul. 2018. "Rekonstruksi Hubungan Komite Sekolah Dan Sekolah Sebagai 
Upaya Meningkatkan Mutu Pendidikan.” Jurnal Pendidikan Dan Kebudayaan Missio 10(2): 223-31.

Mariati, Ulvi et al. 2011. "Studi Kematian Ibu Dan Kematian Bayi Di Provinsi Sumatera Barat: Faktor Determinan Dan Masalahnya." Kesmas: Jurnal Kesehatan Masyarakat Nasional (National Public Health Journal) 5(6): 243-49.

Nasruddin, Nasruddin. 2017. "Tradisi Mappamula (Panen Pertama) Pada Masyarakat Bugis Tolotang Di Sidenreng Rappang (Kajian Antropologi Budaya).” Rihlah: Jurnal Sejarah dan Kebudayaan 5(1): 1-15.

Prasetyaningrum, Susanti. 2017. "Faktor-Faktor Psikologis Yang Mempengaruhi Postpartum Blues." Psympathic: Jurnal Ilmiah Psikologi 4(2): 205-18.

Rofelawaty, Budi. 2018. "Pembangunan Berkelanjutan Berbasis Industri Pariwisata Dan Kearifan Lokal Untuk Peningkatan PAD Provinsi Kalimantan Selatan.” Jurnal Ilmiah Bisnis dan Keuangan 7(2).

Saputro, Anip Dwi. 2017. "Implementasi Pengaturan Karakter, Fisik Dan Jenis Kelamin Janin (Dalam Kajian Tradisi, Sains Dan Islam).” Istawa: Jurnal Pendidikan Islam 2(1): 43-72.

Sari, Lia Susvita, Husaini Husaini, and Bahrul Ilmi. 2017. "Kajian Budaya Dan Makna Simbolis Perilaku Ibu Hamil Dan Ibu Nifas.” Jurnal Berkala Kesehatan 1(2): 78-87.

Wijaya, Roni. 2017. "Pengalaman Ibu Hamil Dalam Perawatan Kehamilan Berbasis Budaya Madura (Studi Kualitatif Di Desa Pegantenan Kabupaten Pamekasan)."

Yuliani, D W I Aniek. 2019. "Pilihan Perawatan Pasca Persalinan Pada Dukun Bayi (Studi Kasus Di Desa Robayan Kecamatan Kalinyamatan Kabupaten Jepara).”

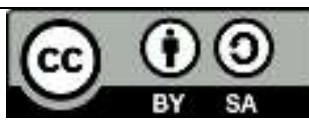

This work is licensed under a Creative Commons Attribution-ShareAlike 4.0 International License. 